\title{
SIMULATION APPROACH FOR SURFACE ROUGHNESS INTERVAL PREDICTION IN FINISH TURNING
}

\author{
Sung, A. N.; Loh, W. P. \& Ratnam, M. M.* \\ School of Mechanical Engineering, Engineering Campus, \\ Universiti Sains Malaysia, 14300 Nibong Tebal, Penang, Malaysia \\ E-Mail: anna.penang@gmail.com, meloh@usm.my, mmaran@usm.my (" Corresponding author)
}

\begin{abstract}
Existing simulation models used in predicting the surface roughness of a workpiece in finish turning are based on an ideal circular cutting tool nose profile. This leads to a single predicted roughness value for a given set of input parameters. In this paper, a simulation approach that considers the random tool nose profile micro-deviations as well as the tool chatter vibration to predict a roughness interval is proposed. The nose profiles used in the simulation were extracted from images of the real cutting tool inserts using sub-pixel edge location. The chatter vibration signal was reconstructed from the measured signals and was superimposed onto the extracted nose profile. The roughness data were computed from 24 simulated workpiece surface profiles and used to determine the $95 \%$ roughness prediction interval. Comparison with the experimental results showed that $100 \%, 96 \%$ and $96 \%$ of the $R_{t}, R_{a}$ and $R_{q}$ roughness values obtained experimentally fell within the predicted roughness intervals.

(Received in March 2015, accepted in September 2015. This paper was with the authors 1 month for 1 revision.)
\end{abstract}

Key Words: Prediction Interval, Nose Profile Micro-Deviation, Surface Roughness, Turning

\section{INTRODUCTION}

Simulation and mathematical models are commonly used to predict the surface roughness of a workpiece in turning [1-3]. Based on the model prediction the correct process parameters can be selected to obtain the required surface finish quality. In spite of the dynamic nature of the turning process the existing surface roughness models are capable of providing only a single roughness value for a given set of input parameters. This is because the models are based on the ideal circular tool nose profiles and ignore the random deviations in the nose profile of the tool. Madic et al. [4] obtained an empirical model for the relationships between the cutting parameters and the surface roughness in the turning of polyamide based material using artificial neural network (ANN). The parameters considered were the cutting speed, feed rate, depth of cut as well as the tool nose radius. The authors performed experiments according to the Taguchi's method and obtained the data for the ANN training. By using the simplex optimization method the authors determined the optimum parameters to obtain the minimum surface roughness. Comparison of the average roughness $R_{a}$ between the modelling and the experiment under optimal conditions showed a difference of $11.8 \%$. This difference could be due to the combined effects of the random deviations in the tool nose profile and the chatter vibration present during the turning.

Bougharriou et al. [5] developed an analytical model to predict the surface profile in turning and burnishing after turning. Their model for the turning was based on several input parameters such as feed rate, nose radius of the tool and radial and axial vibration error signals. Profiles made of linear segments and circular arcs were generated and their model for the maximum peak-to-valley roughness $R_{t}$ produced a single value of roughness for a fixed value of feed rate, depth of cut, tool nose radius and error signals. The difference between the theoretical predictions and the experimental results was attributed to vibrations in the actual machining. However, the influence of the tool nose profile deviation in the real inserts on the surface roughness was not considered in their study. 
In a recently published work the nose profile micro-deviations in the new cutting tools (illustrated in Fig. 1) was found to have a significant effect on the surface roughness of the workpiece [6]. By simulation study alone (without considering vibration) it was shown that $R_{t}$ can deviate as much as $40 \%$ although the tool inserts come from the same batch. The microdeviations present in the tool nose profile result from manufacturing tolerance of $10 \%$ allowed in the ISO3685 - Tool life testing with single point turning tools - standard. In addition to the micro-deviations the nose profiles also deviate randomly from a perfectly circular profile [7]. The combined effects of the tool nose profile imperfections (microdeviation and non-circularity) and the chatter vibrations on the surface roughness of the workpiece have not been investigated in the past.

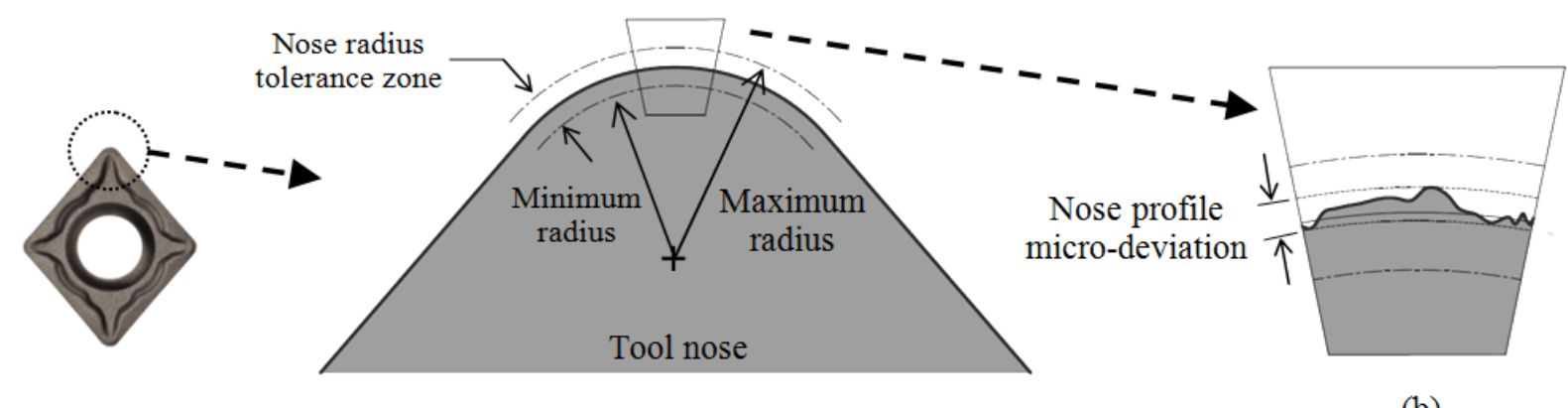

(a)

(b)

Figure 1: Tool nose profile showing micro-deviations.

Some of the early work in modelling the effects of vibration on surface roughness was carried out by Skelton [8]. The author developed theoretical expressions for the $R_{a}$ under dynamic and static conditions. Using the expressions the theoretical and practical roughness values were compared. A 'reasonable' agreement between these values was reported especially at larger feeds. The author assumed that the nose profile of the tool is circular although this assumption could have significant effect on the predicted theoretical roughness values. Lin and Chang [9] proposed a topography simulation model to study the effects of vibration on surface finish in turning. The model incorporates the effects of the relative motion between the cutting tool and the workpiece with the effects of the tool geometry. A circular profile was assumed in the model. This assumption, besides other dynamic effects, could explain the $15 \%$ difference in the surface roughness results from the simulation and the measurement. Qu and Shih [10] presented closed-form solutions of the surface roughness parameters for theoretical surface profile consisting of elliptical arcs. Using both implicit and parametric methods the authors derived models for $R_{t}, R_{a}$ and $R_{q}$ (root mean squared roughness). The authors assumed that the nose geometry can be described by using a simple mathematical equation, although this assumption is far from reality.

Many other researchers have developed prediction models for the surface roughness based on experimental data. The techniques employed include response surface methodology (RSM) combined with factorial design approach [11], RSM combined with data extracted from workpiece surface profile simulated from images of tool inserts [12], statistical models based on experimental data [13] and artificial neural network-based methodologies [14-16]. Hessainia et al. [17] developed a surface roughness model in hard turning by exploiting the response surface model. The main input parameters in the model were cutting speed, depth of cut, feed rate and tool vibrations. Simunovic et al. [18] developed two models for the prediction of surface roughness in face milling. One was based on a regression model while the other was based on neural networks. Although an error of less than $5 \%$ was reported when comparing the prediction and experimental results the effect of tool nose profile deviation was not a factor considered in their model. Lee et al. [19] used vision-based data and abductive 
network to develop a model for surface roughness in turning. Several image features extracted from the work piece were used as input in the network. The authors showed that the surface roughness predicted by the model using parameters measured by the computer vision system have reasonable accuracy compared with the experimental results.

Cus and Zuperl [20] proposed a model-based controller to control the turning process to obtain a constant surface roughness value. The control model was used to change the feed rate in real time in order to keep the surface roughness constant. The correlation between the surface roughness and cutting forces obtained experimentally was used to provide the functional correlation with the controllable factors. Although the simulation study showed that the actual $R_{a}$ value is close to the reference value after applying the control action, the effects of the tool-to-tool nose profile variation on the cutting force-surface roughness relationship and the control action are unknown. Pare et al. [21] determined the optimum machining conditions for the end milling of composite materials using gravitational genetic algorithm (GSA). The cutting speed, feed rate, the depth of cut and the step-over ratio were considered as the input parameters whereas the surface roughness is taken as the output parameter. The validation results showed that the maximum difference in the actual and predicted $R_{a}$ values is $12.0 \%$. This difference could partly be attributed to the deviation in the cutting tool nose profile when the experiment was repeated using a different tool insert. Krolczyk et al. [22] compared eight amplitude and five material ratio parameters measured using Infinite Focus Measurement (IFM) machine for two different production methods, namely turning and Fused Deposition Modeling (FDM). The effect of the tool nose profile micro-deviations on the measured parameters, however, was not considered. Wan et al. [23] used numerical approach to investigate the effects of four common types of tool edge geometries on the formation of dead metal zone and their effects on the stress and temperature distribution. The authors reported that the edge geometry did not affect the chip removal process significantly. They also found that the chamfer and double chamfer tool had almost the same effect on the residual stress distribution as the honed and sharp tools. As in other simulation studies, the authors did not take into consideration the random micro-deviations in the nose profile caused by the manufacturing tolerances.

Although much work has been reported in the literature on the modelling and prediction of surface roughness in machining, the main limitations of these researches can be summarized as follows:

1. Mathematical models developed in the past for predicting the surface roughness assume a circular tool nose profile. This is because it is impossible to develop mathematical models for non-circular random profiles superimposed with micro-deviations.

2. Empirical models and artificial intelligence methods for roughness prediction need a large amount of experimental data and produce a single value of surface roughness for a set of input parameters. The large difference between the predicted and the experimental roughness values show that the random nose profile deviation needs to be considered in the models.

Surface formation during machining is a complex process. Experimental results have shown that when the machining is repeated under identical conditions it is impossible to obtain identical roughness values [24-25]. The deviations in the roughness observed in these studies can be attributed to the random tool nose profile deviations and the random vibrations present during machining Thus, the mathematical models and empirical methods developed in the past that produce a single roughness value for a set of input parameters are inadequate for the accurate prediction of the surface roughness. Since the tool nose has a significant effect on the roughness of the machined workpiece and the nose profile varies randomly from tool to tool, improved prediction accuracy can only be obtained if it is possible to obtain a prediction interval for the surface roughness. 
The objective of this paper is to propose a new simulation approach that can be used to obtain a prediction interval for the surface roughness of the workpiece by taking into consideration the tool nose profile micro-deviations and chatter vibrations. The main advantage of the proposed simulation method compared to the empirical models is that extensive experimental work to generate the roughness data is not needed. The workpiece profile is generated using simulation based on the image of the actual cutting insert, which contains the nose profile micro-deviations. A detailed description of the simulation and the experimental procedure is given in the subsequent sections.

\section{METHODOLOGY}

\subsection{Simulation method to obtain surface roughness parameters}

The input data in the proposed simulation approach are as follows: tool nose image, side cutting edge angle (SCEA), feed rate and the vibration signals. The specifications of the tool are given in Table I. The feed rate was fixed at $0.24 \mathrm{~mm} / \mathrm{rev}$ and the vibration signal was measured once. The algorithm to generate the simulated surface profile and to determine the roughness parameters $R_{t}, R_{a}$ and $R_{q}$ is shown in Fig. 2. These three parameters are the most commonly used roughness parameters in the industry and in research [26]. The algorithm was coded in MATLAB (Version 2014b) for the computer simulation of the workpiece profile.

Table I: The specifications of the tool insert.

\begin{tabular}{|l|c|l|c|}
\hline Tool shape: & Rhombic & No. of edges: & 4 \\
\hline Insert model: & DNMG150608 & Inclination angle: & $-9^{\circ}$ \\
\hline Tool holder: & DDNNN2525M15 & Rake angle: & $-5^{\circ}$ \\
\hline Nominal radius: & $0.8 \mathrm{~mm}$ & Major cutting edge angle: & $62.5^{\circ}$ \\
\hline Included angle: & $55^{\circ}$ & Side cutting edge angle (SCEA): & $62.5^{\circ}$ \\
\hline
\end{tabular}

In Stage 1 a the tool nose image (Fig. 3 a) was captured using a commercial 3-D optical metrology system (Alicona Infinitefocus, Alicona Imaging Ltd., Austria). The tool was fitted to the tool holder when the image was captured. Thus, the image includes the effect of the inclination and rake angles on the nose orientation. A $5 \times$ magnification was selected to capture the rounded tool nose as well as the left and right straight flank portions at a resolution of $1.754 \mu \mathrm{m} / \mathrm{pixel}$. The original image was read as a RGB image and converted to a grayscale image in a 2-D matrix $F(x, y)$. The image was pre-processed using a $3 \times 3$ median filter for noise suppression. The nose profile was extracted using the sub-pixel edge location method [6]. The extracted nose profile superimposed onto the original image is shown in Fig. $3 \mathrm{~b}$. The enlarged image in Fig. $3 \mathrm{c}$ shows the nose profile detection in sub-pixel accuracy. Fig. $3 \mathrm{~d}$ shows the extracted nose profile in the $x-y$ coordinates. The nose profile was rotated to be relocated to the appropriate SCEA as detailed in [6].

Mechanical vibration in a metal cutting process can be classified into three types, namely free, forced and chatter vibration [27]. The noisy signal is a combination of all three types of vibrations. Free and forced vibrations are the unwanted signals or noises that interfere with the measurement of the chatter vibration. The random noise signals cannot be cancelled out but their average effect can be reduced. The noise signals were measured when the machine is running idle. Stage $1 \mathrm{~b}$ of the algorithm is the signal processing stage used to extract the displacement-spatial vibration signal $h\left(d_{s}\right)$.

Fig. 4 shows a block diagram of the chatter vibration signal (considered as clean signal) extraction method. A threshold value determined from the noise signal and a high pass filter were used to process the noisy signal in order to retrieve the clean (chatter) vibration signal. 


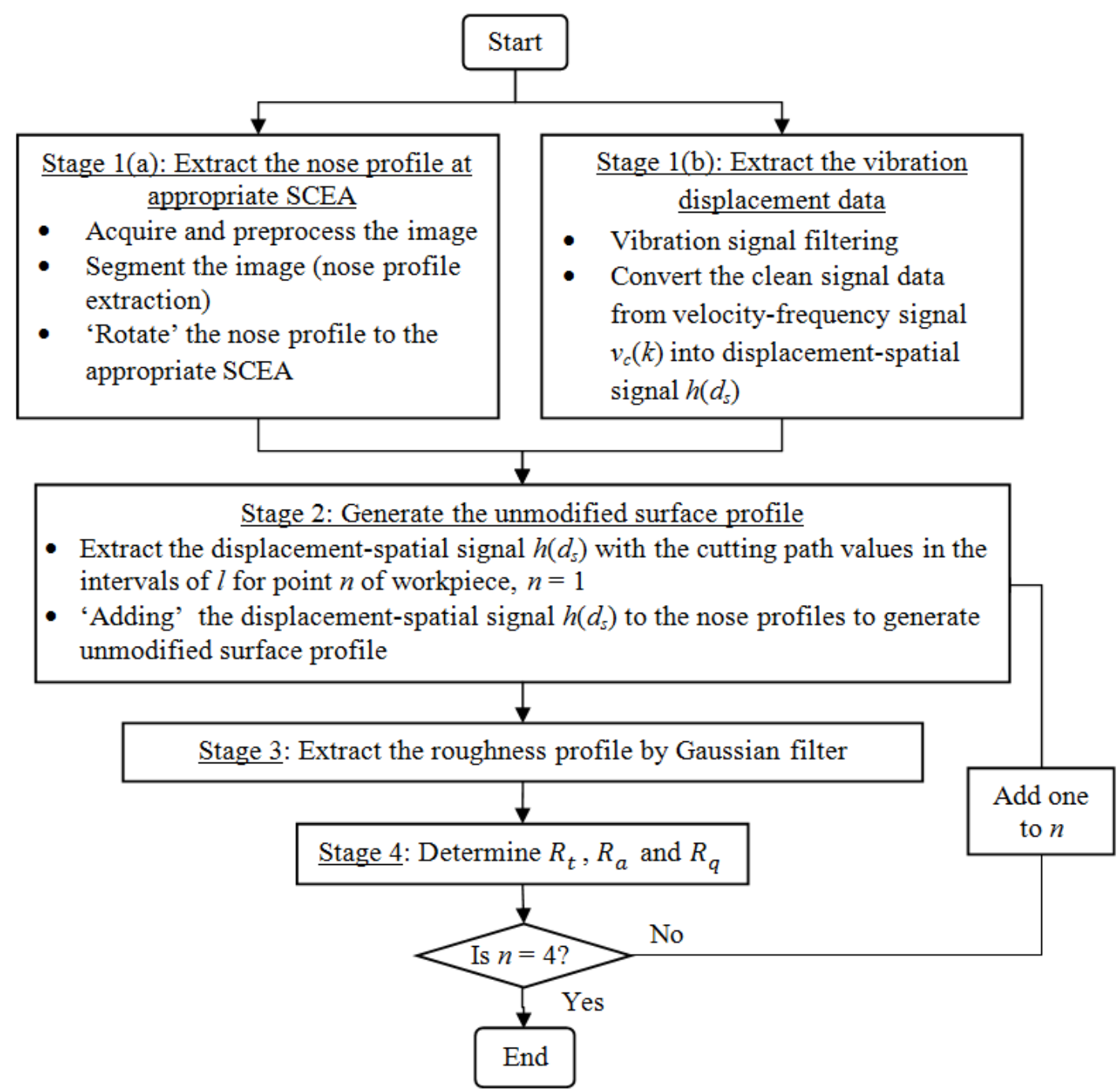

Figure 2: Flow chart of the algorithm of simulation approach.

Firstly, the measured noise velocity-time signal $v_{e}(n)$ data as shown in Fig. 5 a was loaded into MATLAB. The data consists of the time and the velocity of vibration amplitude in 16384 samples along a period of 1.28 seconds. The velocity value is positive when the workpiece is moving towards the vibrometer optic. By using Discrete Fourier Transformer (DFT), the time-domain noise signal $v_{e}(n)$ was transformed into the frequency-domain noise signal $v_{e}(k)$ shown in Fig. 5 b. The DFT was followed by filter threshold value estimation. The distribution of the velocity amplitude in the frequency domain was observed. The amplitude count of velocity was found to fall densely within the range of 0 to $0.2 \times 10^{-3} \mathrm{~m} / \mathrm{s}$. The count becomes less dense after $0.5 \times 10^{-3} \mathrm{~m} / \mathrm{s}$ whereby only six peaks were higher than $0.5 \times 10^{-3}$ $\mathrm{m} / \mathrm{s}$. Thus, the threshold value was set to $0.5 \times 10^{-3} \mathrm{~m} / \mathrm{s}$.

The noisy velocity-time signal $v_{y}(n)$ was measured during the turning process. The data consists of 98303 samples for time duration of 7.68 seconds. Upon eliminating the velocity amplitude smaller than the threshold value, it was observed that the noisy vibration signal appeared in the frequencies below $2 \mathrm{~Hz}$ and $2000 \mathrm{~Hz}$ to $3210 \mathrm{~Hz}$. This signal was further filtered by applying a high pass filter of $2 \mathrm{~Hz}$ to obtain the clean velocity-frequency signal $v_{c}(k)$ with the significant vibration frequency components present in between 2000 to $3210 \mathrm{~Hz}$. The $v_{c}(k)$ signal was converted into 'clean' displacement-frequency signal $h_{c}(k)$ given by

$$
h_{c}(k)=\frac{v_{c}(k)}{2 \pi i(k-1)} \quad k=2, \ldots, N
$$




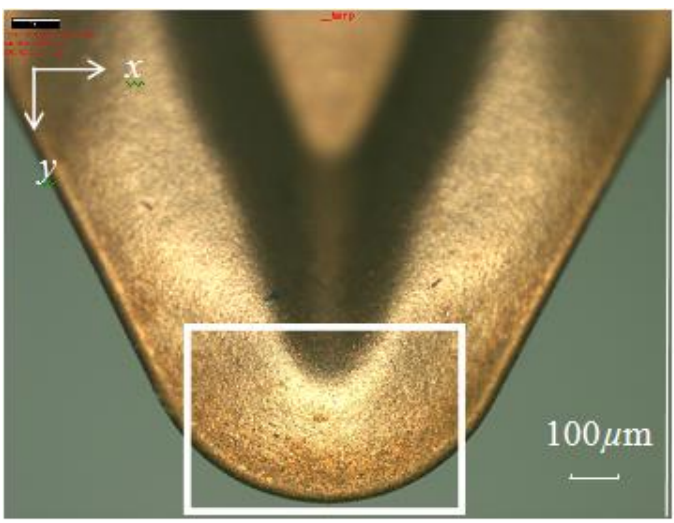

(a)

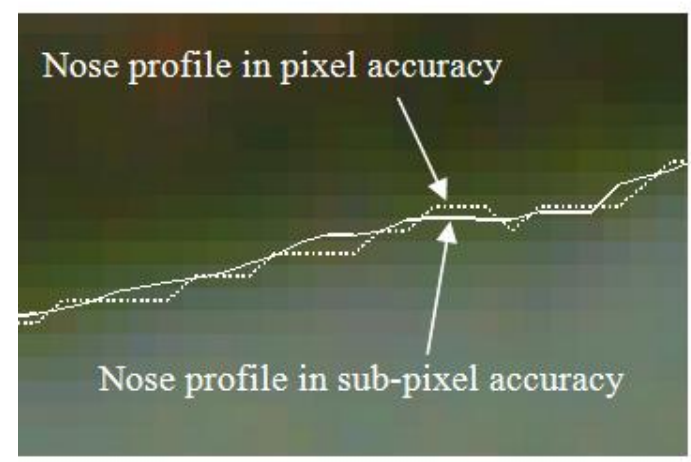

(c)

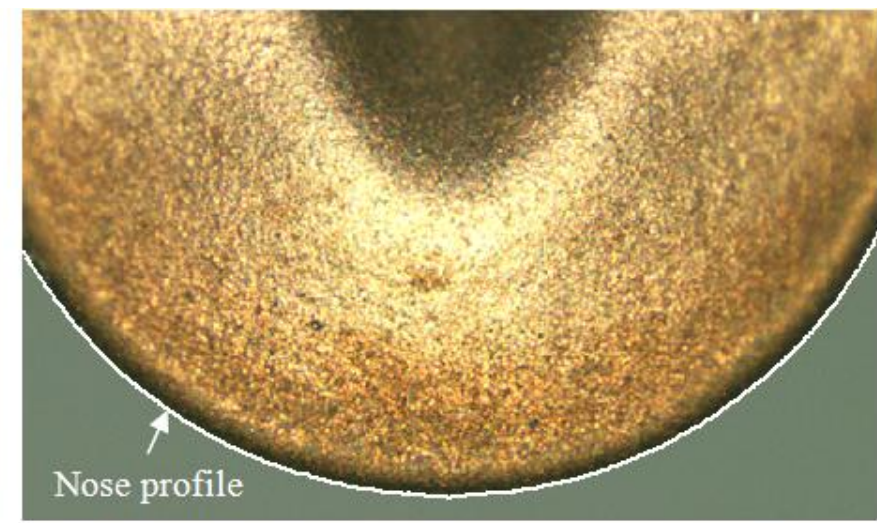

(b)

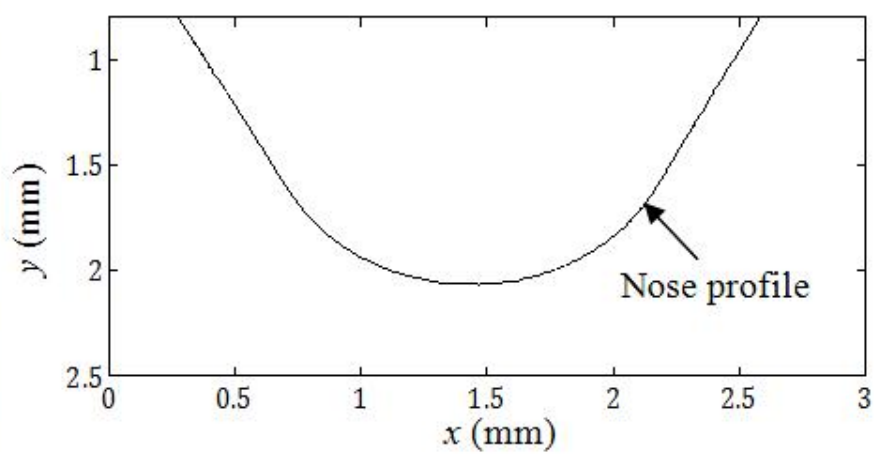

(d)

Figure 3: a) Image of tool nose; b) the plot of nose profile superimposed onto the image in the zoomed view of the selected region of a); c) the plot of nose profile in partly enlarged view; d) the plot of nose profile in $x-y$ coordinate.

The displacement-time signal $h_{c}(n)$ (Fig. 6) was computed by applying Inverse Discrete Fourier Transformer (IDFT) on the 'clean' displacement-frequency signal $h_{c}(k)$. The displacement-time signal $h_{c}(n)$ (displacement of the workpiece in the radial direction with respect to time) was converted into displacement-spatial signal $h\left(d_{s}\right)$ (displacement of the workpiece in radial direction with respect to the cutting path in the circumferential direction). The time $t$ was converted into displacement along cutting path $d_{s}$ using the following equation:

$$
d_{s}=\frac{t \pi D V}{60}
$$

where $D$ is the diameter of workpiece (mm) and $V$ is the spindle speed (rpm).

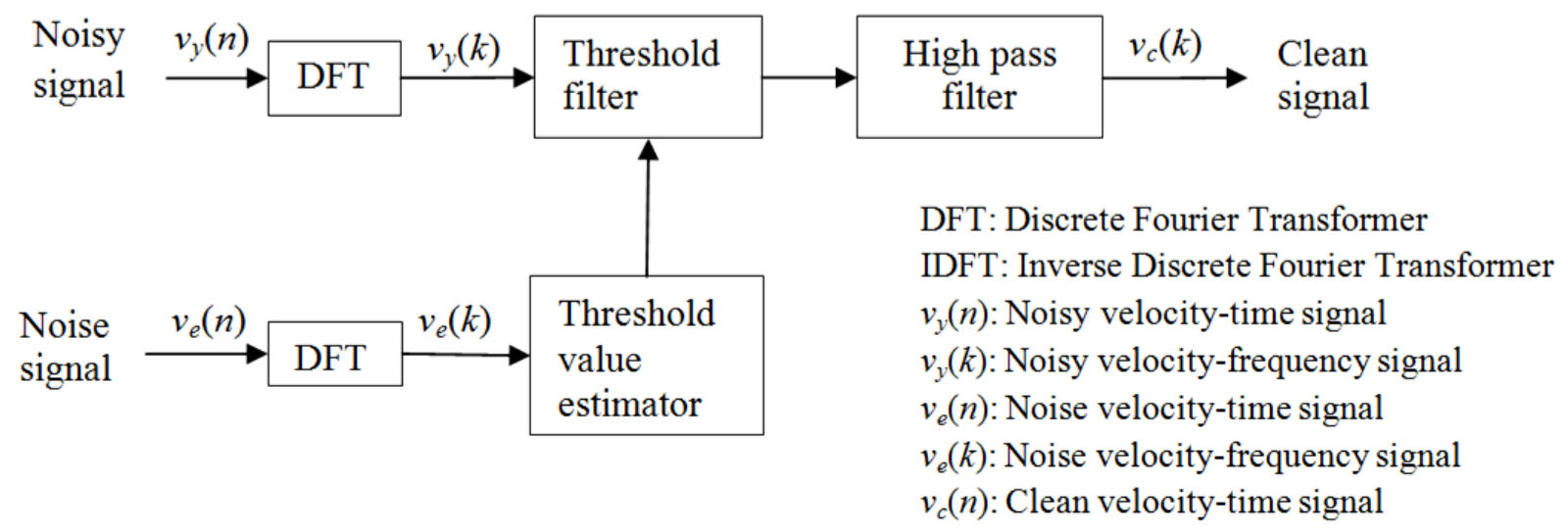

Figure 4: Block diagram configuration of a clean signal extraction. 


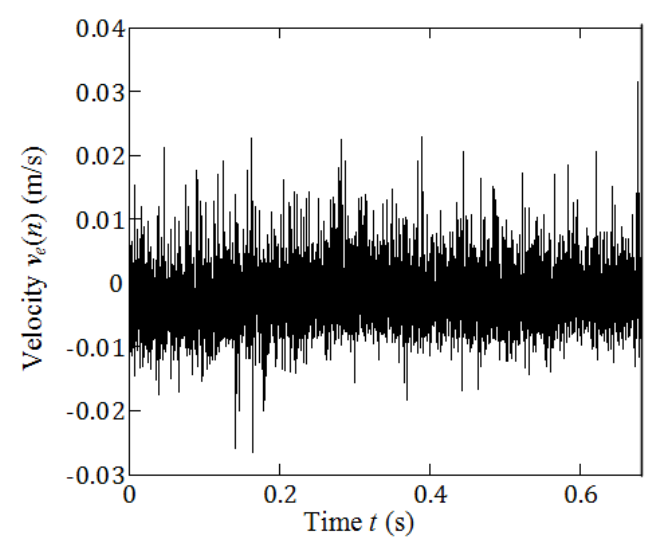

(a)

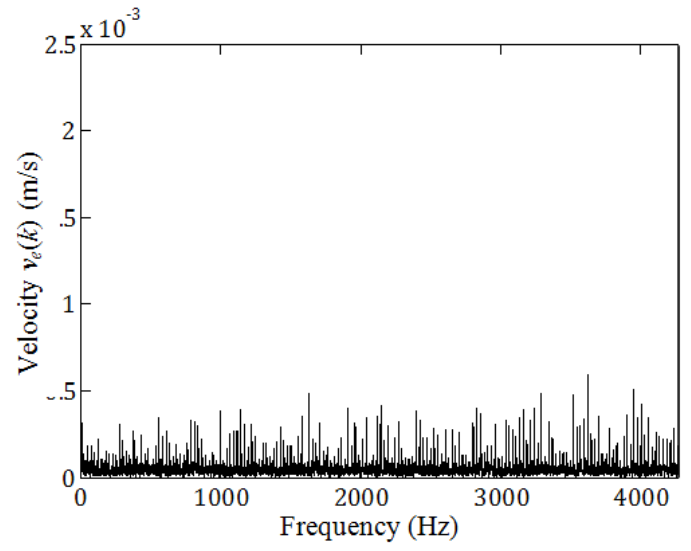

(b)

Figure 5: a) The noise velocity-time signal; b) noisy velocity-frequency signal.

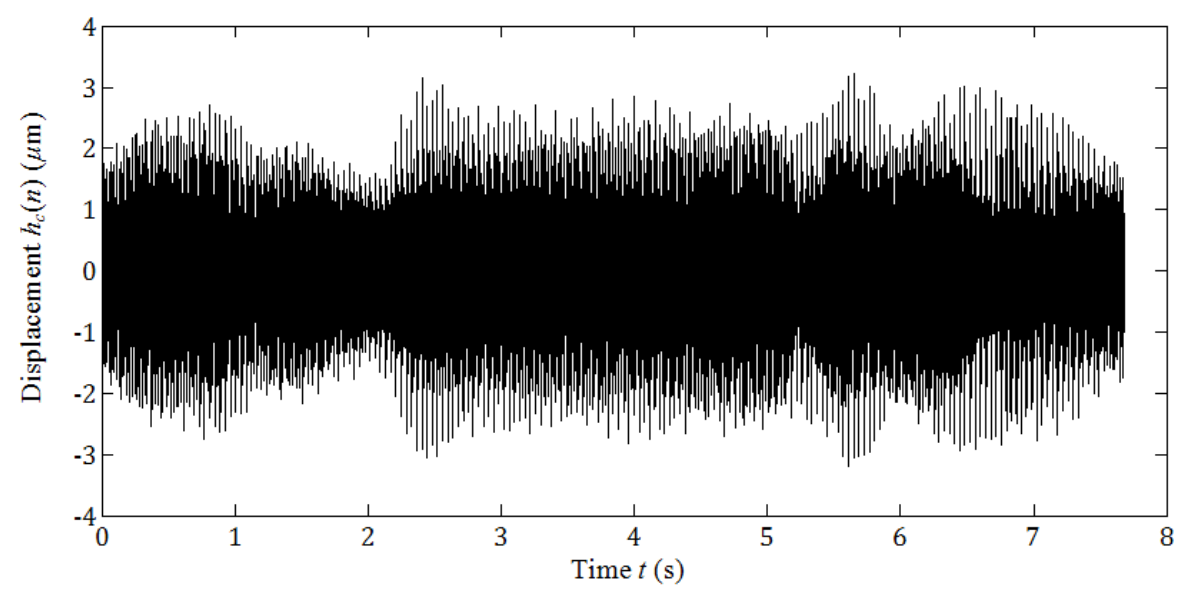

Figure 6: Displacement-time signal.

The surface profile is defined along the longitudinal direction while the chatter vibration was measured along the cutting path as shown in Fig. 7 a. The length of the cutting path $l$ in one revolution is approximately equal to the circumference of the face plane of the workpiece. The $h\left(d_{s}\right)$ signal data at each interval $l$ space apart in the cutting path describe the radial displacement of the nose tips along the longitudinal direction. The surface profile of the workpiece was generated by adding up the radially displaced nose tips along the longitudinal direction as shown in Fig. $7 \mathrm{~b}$. By repeating this process at the four different points on the workpiece labelled as '1a', '1b', '1c' and ' $1 d$ ' (Fig. 7 a) four surface profiles were generated for the same 'cutting' conditions.

Since the generated profile is comprised of form, waviness and roughness, in Stage 3 of the algorithm a Gaussian filter was applied to extract the roughness profile [28]. The Gaussian mean line was obtained from the convolution of a weighting function and the unmodified profile. The weighting function has the equation of the Gaussian function with a cut-off sampling length $\lambda$ and is given by [29]:

$$
s\left(x^{\prime}\right)=\frac{1}{\alpha \lambda} e^{\left[-\pi\left(\frac{x^{\prime}}{\alpha \lambda}\right)^{2}\right]}
$$

where $x^{\prime}$ is the distance from the centre (maximum) of the weighting function and $\alpha$ is a constant to provide $50 \%$ transmission characteristic at the cut-off wavelength $\lambda$. The value of $\alpha$ is 0.4697 . The difference between the unmodified profile and the mean line is the simulated roughness profile shown in Fig. 8. It is interesting to note that the simulated profile contains the effects of the nose profile micro-deviations that manifests as high-frequency fluctuations. 


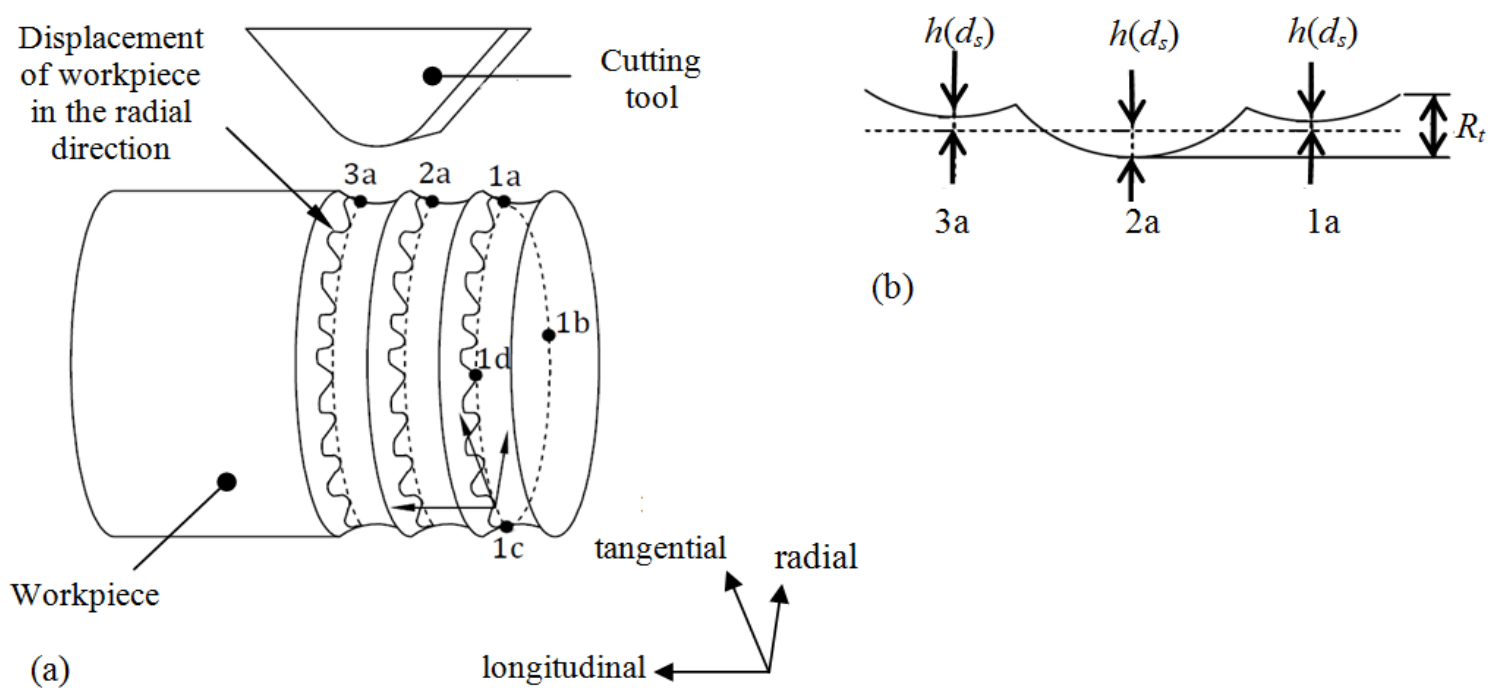

Figure 7: a) Workpiece in presence of chatter vibration; b) the respective surface profile.

In Stage $4, R_{a}$ and $R_{q}$ values were determined from the roughness profile $P_{r}(x, y)$. The assessment of $R_{a}$ and $R_{q}$ were made over five sampling lengths based on $0.8 \mathrm{~mm}$ intervals. The $R_{a}$ and $R_{q}$ values were determined from the following equations while $R_{t}$ was given by the maximum peak-to-valley height of the profile within five sampling lengths:

$$
\begin{gathered}
R_{a}=\frac{1}{n} \sum_{i=1}^{n}\left|y_{i}-\bar{y}\right| \\
R_{q}=\sqrt{\frac{1}{n} \sum_{i=1}^{n}\left|y_{i}-\bar{y}\right|^{2}}
\end{gathered}
$$

where $n$ represents sampled points along the profile.

$$
\bar{y}=\frac{1}{n} \sum_{i=1}^{n}\left(y_{i}-y_{\min }\right)
$$

where $y_{\min }$ is a minimum $y$ value in the profile $P_{r}$ and $y_{i}$ the $i^{\text {th }} y$ value in the profile $P_{r}$.

Stages 2 to 4 were repeated for four sets of selected $h\left(d_{s}\right)$ data acting on different points of the workpiece. The four surface profiles generated are equivalent to the profiles measured at four different points of surface by rotating the workpiece about its axis through the angular position of $90^{\circ}$. This procedure was repeated for all 24 tool tips labelled as tool edge 1 to tool edge 24 .

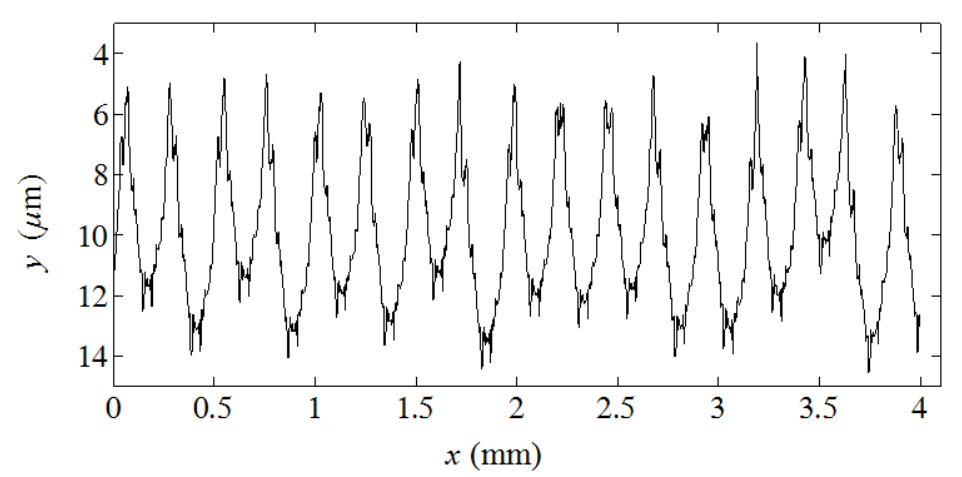

Figure 8: Simulated roughness profile.

\subsection{Calculation of prediction intervals of surface roughness}

By using the 24 simulated surface roughness data as the input samples the prediction intervals for $R_{t}, R_{a}$ and $R_{q}$ were calculated. The prediction intervals within which the predicted surface 
roughness data will fall was determined without conducting any experiment. The $95 \%$ prediction interval for the surface roughness data $R_{s(N+1)}$ with sample mean $\overline{R_{S}}$ and size of the sample $N(N=24)$ are calculated as [29]:

$$
\overline{R_{S}}-t_{0.975, N-1} S_{R} \sqrt{1+\frac{1}{N}} \leq R_{S(N+1)} \leq \overline{R_{S}}+t_{0.975, N-1} S_{R} \sqrt{1+\frac{1}{N}}
$$

where $t_{0.975, N-1}$ is the $97.5 \%$ quantile of a Student's $t$-distribution with $N-1$ degrees of freedom. For $N=24, t_{0.975, N-1}$ is equal to 2.096 [30].

Since the prediction interval in Eq. (7) is valid only for normally distributed data the normality assumption of the surface roughness data was checked by using Lilliefor test [31]. Based on the test all three sets of simulation data for $R_{t}, R_{a}$ and $R_{q}$ were found to come from a normally distributed population.

\subsection{Experimental surface roughness data}

The experimental surface roughness data were obtained from the previous work [6]. The length of the workpiece was $90 \mathrm{~mm}$ while the distance machined was $10 \mathrm{~mm}$. A stylus type roughness tester (Surfcom 130A) was used to measure the surface roughness with a sampling length $0.8 \mathrm{~mm}$. Four repeated readings were taken at different points by rotating the workpiece about its axis through $90^{\circ}$ and the average value was calculated. These measured data were used to determine the accuracy of the roughness prediction interval based on the simulated data. Since the machining duration was only $12.6 \mathrm{~s}$ the effect of tool nose wear was neglected. The experimental work in this study is focused on measuring the vibration data used in the simulation. The vibration data were measured using the PSV-400 contactless 3-D scanning laser vibrometer. Fig. 9 shows the set-up of the experiment. The vibrometer is noncontacting, has a wide-frequency bandwidth (up to $80 \mathrm{kHz}$ ) and a velocity resolution of 0.1 $\mu \mathrm{m} / \mathrm{s}$. The velocity-time vibration data were collected during the cutting conditions and when the machine was running idle. The laser beam of the vibrometer was focused onto the workpiece $15 \mathrm{~mm}$ from the workpiece free end.

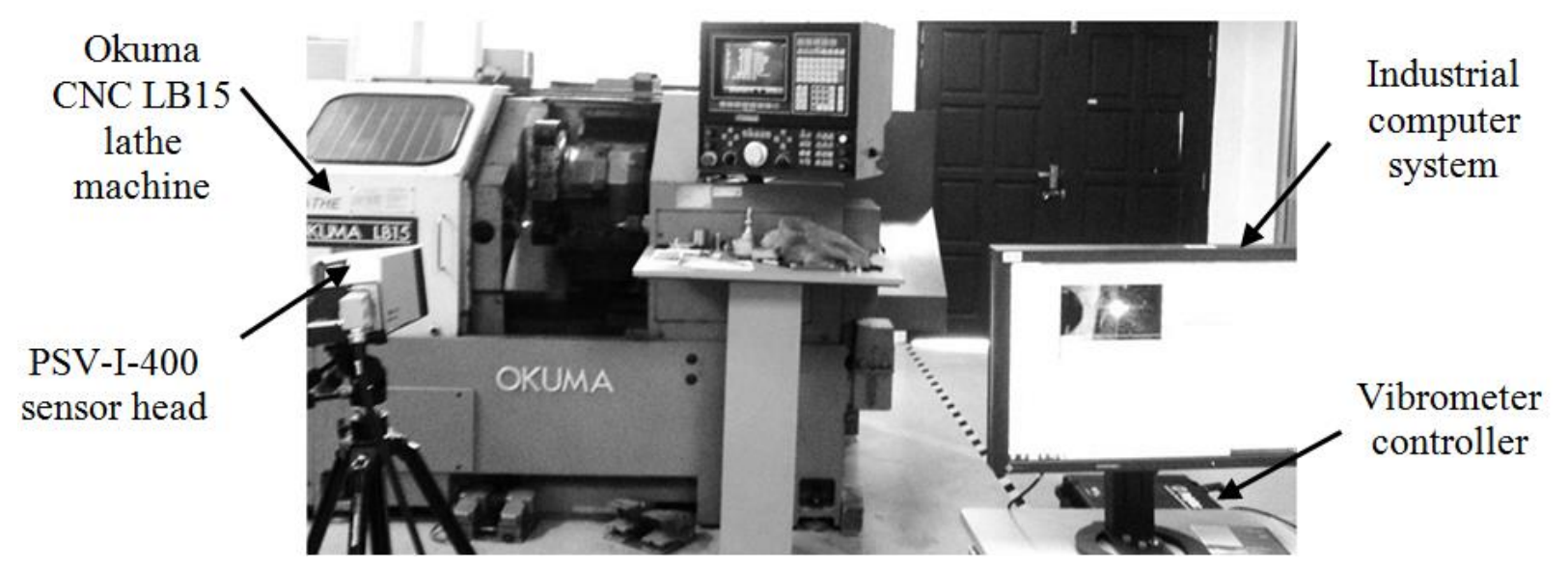

Figure 9: The experimental setup.

\section{RESULTS AND DISCUSSIONS}

The minimum, maximum and average roughness values obtained from the simulation are shown in Table II. These data were obtained from the four points along the cutting direction (tangential) shown in Fig. 7 a for each tool edge. The simulation results show that although the inserts come from the same batch the $R_{t}, R_{a}$ and $R_{q}$ values vary as much as $36.5 \%, 41.1 \%$ and $37.5 \%$, respectively. This variation is caused by the combined effect of the micro- 
deviations and non-circularity in the profile of the tool tips as well as the chatter vibration. Fig. 10 a shows a 3-D image of one of the tool edges where the profile measurement was carried out using the Alicona Infinitefocus 3-D metrology system. The measured profile (Fig. $10 \mathrm{~b}$ ) clearly shows the presence of the nose profile micro-deviations. The effects of these deviations are visible in the simulated profile in Fig. 8.

Table II: Minimum, maximum and average roughness values obtained by simulation.

\begin{tabular}{|c|c|c|c|c|c|c|c|c|c|c|}
\hline \multirow{2}{*}{$\begin{array}{l}\text { Cutting } \\
\text { tool no. }\end{array}$} & \multirow{2}{*}{$\begin{array}{c}\text { Tool } \\
\text { edge no. }\end{array}$} & \multicolumn{3}{|c|}{$\boldsymbol{R}_{t}(\mu \mathrm{m})$} & \multicolumn{3}{|c|}{$\boldsymbol{R}_{a}(\mu \mathrm{m})$} & \multicolumn{3}{|c|}{$\boldsymbol{R}_{\boldsymbol{q}}(\mu \mathrm{m})$} \\
\hline & & Min. & Max. & Avg. & Min. & Max. & Avg. & Min. & Max. & Avg. \\
\hline \multirow{4}{*}{1} & 1 & 14.4 & 14.7 & 14.6 & 2.6 & 2.6 & 2.6 & 3.1 & 3.1 & 3.1 \\
\hline & 2 & 11.7 & 12.2 & 11.9 & 2.1 & 2.2 & 2.2 & 2.6 & 2.7 & 2.7 \\
\hline & 3 & 10.8 & 11.3 & 11.1 & 2.3 & 2.3 & 2.3 & 2.7 & 2.7 & 2.7 \\
\hline & 4 & 11.7 & 12.7 & 12.3 & 2.3 & 2.4 & 2.4 & 2.8 & 2.8 & 2.8 \\
\hline \multirow{4}{*}{2} & 5 & 10.7 & 11.3 & 11.1 & 2.3 & 2.3 & 2.3 & 2.7 & 2.7 & 2.7 \\
\hline & 6 & 11.3 & 12.1 & 11.9 & 2.4 & 2.5 & 2.5 & 2.8 & 2.9 & 2.9 \\
\hline & 7 & 10.5 & 11.4 & 11.0 & 2.3 & 2.3 & 2.3 & 2.7 & 2.8 & 2.7 \\
\hline & 8 & 11.5 & 12.9 & 12.0 & 2.1 & 2.2 & 2.2 & 2.5 & 2.6 & 2.6 \\
\hline \multirow{4}{*}{3} & 9 & 11.4 & 12.8 & 12.3 & 2.5 & 2.5 & 2.5 & 2.9 & 3.0 & 2.9 \\
\hline & 10 & 11.3 & 11.8 & 11.6 & 2.3 & 2.3 & 2.3 & 2.7 & 2.8 & 2.7 \\
\hline & 11 & 12.2 & 12.9 & 12.7 & 2.4 & 2.4 & 2.4 & 2.9 & 2.9 & 2.9 \\
\hline & 12 & 10.7 & 11.4 & 11.1 & 2.1 & 2.2 & 2.1 & 2.6 & 2.6 & 2.6 \\
\hline \multirow{4}{*}{4} & 13 & 11.3 & 12.1 & 11.7 & 2.6 & 2.6 & 2.6 & 3.0 & 3.0 & 3.0 \\
\hline & 14 & 12.5 & 13.0 & 12.8 & 2.7 & 2.8 & 2.7 & 3.2 & 3.2 & 3.2 \\
\hline & 15 & 10.2 & 11.1 & 10.8 & 2.2 & 2.2 & 2.2 & 2.5 & 2.6 & 2.6 \\
\hline & 16 & 11.4 & 12.0 & 11.7 & 2.5 & 2.5 & 2.5 & 2.9 & 2.9 & 2.9 \\
\hline \multirow{4}{*}{5} & 17 & 9.5 & 10.8 & 10.3 & 1.7 & 1.8 & 1.8 & 2.1 & 2.2 & 2.1 \\
\hline & 18 & 12.9 & 13.8 & 13.3 & 2.7 & 2.7 & 2.7 & 3.1 & 3.2 & 3.1 \\
\hline & 19 & 10.1 & 11.3 & 10.7 & 1.9 & 2.0 & 2.0 & 2.3 & 2.4 & 2.3 \\
\hline & 20 & 12.0 & 12.8 & 12.4 & 2.5 & 2.5 & 2.5 & 2.9 & 3.0 & 2.9 \\
\hline \multirow{4}{*}{6} & 21 & 10.7 & 11.5 & 11.0 & 2.3 & 2.4 & 2.4 & 2.7 & 2.8 & 2.8 \\
\hline & 22 & 14.0 & 14.9 & 14.4 & 2.6 & 2.7 & 2.7 & 3.1 & 3.2 & 3.1 \\
\hline & 23 & 12.6 & 13.8 & 13.2 & 2.3 & 2.3 & 2.3 & 2.8 & 2.8 & 2.8 \\
\hline & 24 & 12.6 & 13.4 & 12.9 & 2.2 & 2.3 & 2.3 & 2.6 & 2.7 & 2.7 \\
\hline
\end{tabular}

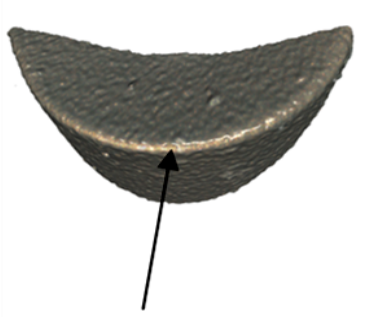

Measurement area

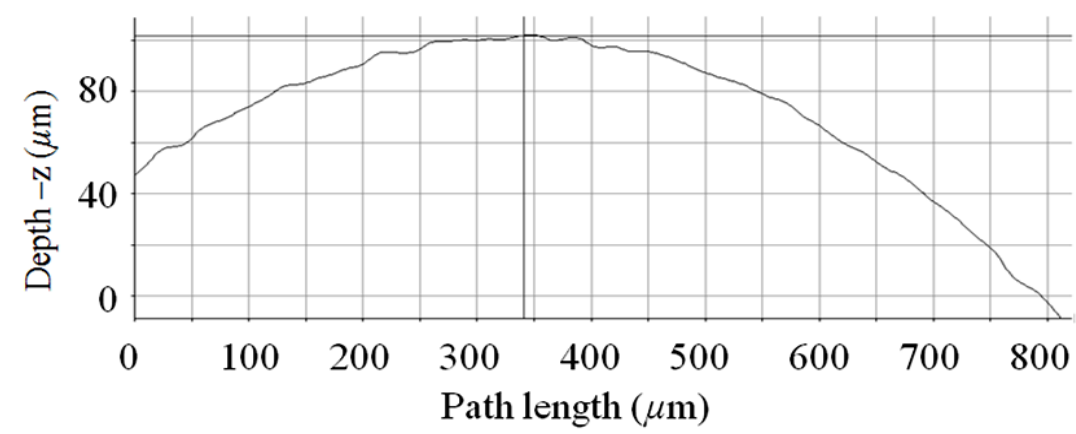

(b)

Figure 10: a) Nose profile extraction by profile measurement; b) the correspondence extracted nose profile.

Figs. $11 \mathrm{a}$ and $11 \mathrm{c}$ show two simulated profiles while Figs. $11 \mathrm{~b}$ and $11 \mathrm{~d}$ show the actual profiles measured using a stylus profiler for tool edges 6 and 11. The averaging effect of the stylus tip can be clearly seen in the measured profiles. Short wavelength (high frequency) fluctuations in the profile were averaged out by the filtering effect of the rounded stylus tip. The general trends of the workpiece surface were, however, preserved in most of the cases. 


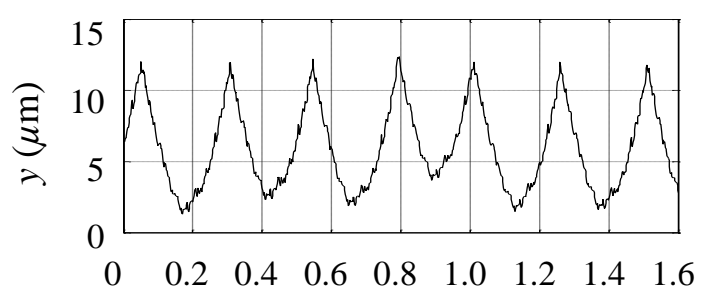

(a)

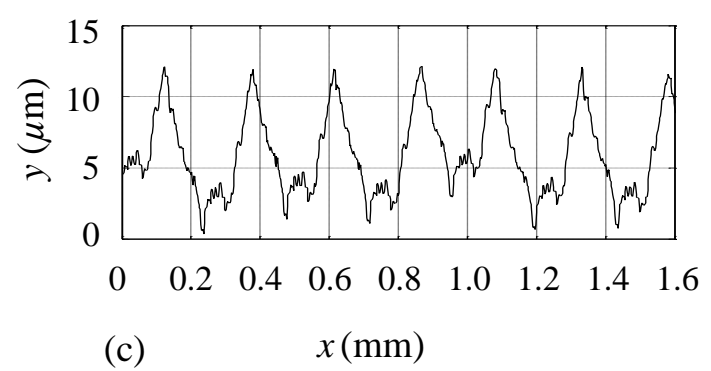

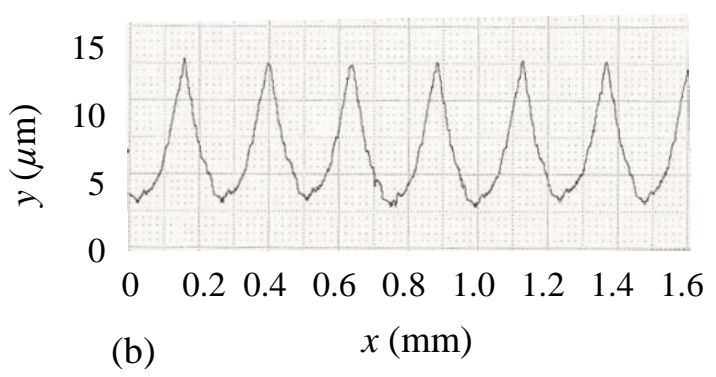

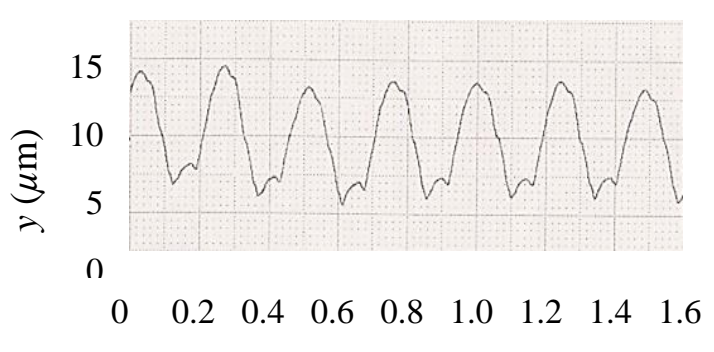

(d) $x(\mathrm{~mm})$

Figure 11: Comparison of simulated and measured profiles: a) and b) simulated and measured profiles for tool edge $6 ;$ c) and d) measured and simulated profiles for tool edge 11.

The $95 \%$ roughness prediction intervals determined using Eq. (7) are shown graphically in Figs. $12 \mathrm{a}, \mathrm{b}$ and $\mathrm{c}$ together with the experimental data. The prediction interval for each parameter and the percentage of experimental data that fall within the interval are shown in Table III. Although the experimental and simulation data fluctuate randomly due to the random nose profile deviation and chatter vibrations the mean absolute difference in the roughness values deviate at most by $9.9 \%$. The results showed that $100 \%, 96 \%$ and $96 \%$ of the experimentally obtained roughness data fell within the $97.5 \%$ prediction interval. This shows that the proposed simulation is a reliable approach to obtain the roughness prediction interval.

Table III: Analysis of surface roughness data obtained from the simulation method.

\begin{tabular}{|l|c|c|c|}
\hline Roughness Parameter & $\boldsymbol{R}_{\boldsymbol{t}}$ & $\boldsymbol{R}_{\boldsymbol{a}}$ & $\boldsymbol{R}_{\boldsymbol{q}}$ \\
\hline Mean $(\mu \mathrm{m})$ & 12.03 & 2.36 & 2.79 \\
\hline Standard deviation $(\mu \mathrm{m})$ & 1.26 & 0.23 & 0.25 \\
\hline 97.5\% roughness prediction interval $(\mu \mathrm{m})$ & $12.03 \pm 2.66$ & $2.36 \pm 0.49$ & $2.79 \pm 0.53$ \\
\hline $\begin{array}{l}\text { Mean absolute difference between simulated } \\
\text { and experimental data }(\%)\end{array}$ & $9.9 \%$ & $8.8 \%$ & $7.6 \%$ \\
\hline $\begin{array}{l}\text { Percentage of experimental data that fall within } \\
\text { the prediction interval }(\%)\end{array}$ & $100 \%$ & $96 \%$ & $96 \%$ \\
\hline
\end{tabular}

\section{CONCLUSION}

A simulation approach to obtain the roughness prediction interval by considering the nose profile micro-deviations and chatter vibration has been proposed. Inputs, such as the actual insert image, SCEA, feed rate and vibration signal were used to obtain the roughness prediction interval. Comparison with experimental data shows that $100 \%$ of $R_{t}, 96 \%$ of the $R_{a}$ and $R_{q}$ data fell within the prediction intervals. Unlike the existing simulation methods that yield a single value of the predicted surface roughness, our approach produces a roughness interval as encountered in the real experiments. By combining chatter vibration and nose profile micro-deviations it is possible to generate large amount of roughness data without having to carry out actual machining. These data can be used to access the quality of the 
cutting tools or used in prediction methods based on artificial neural networks. Although this study was limited to one type of cutting tool, namely rhombic, the proposed simulation procedure can be applied to other tool types.

(a)

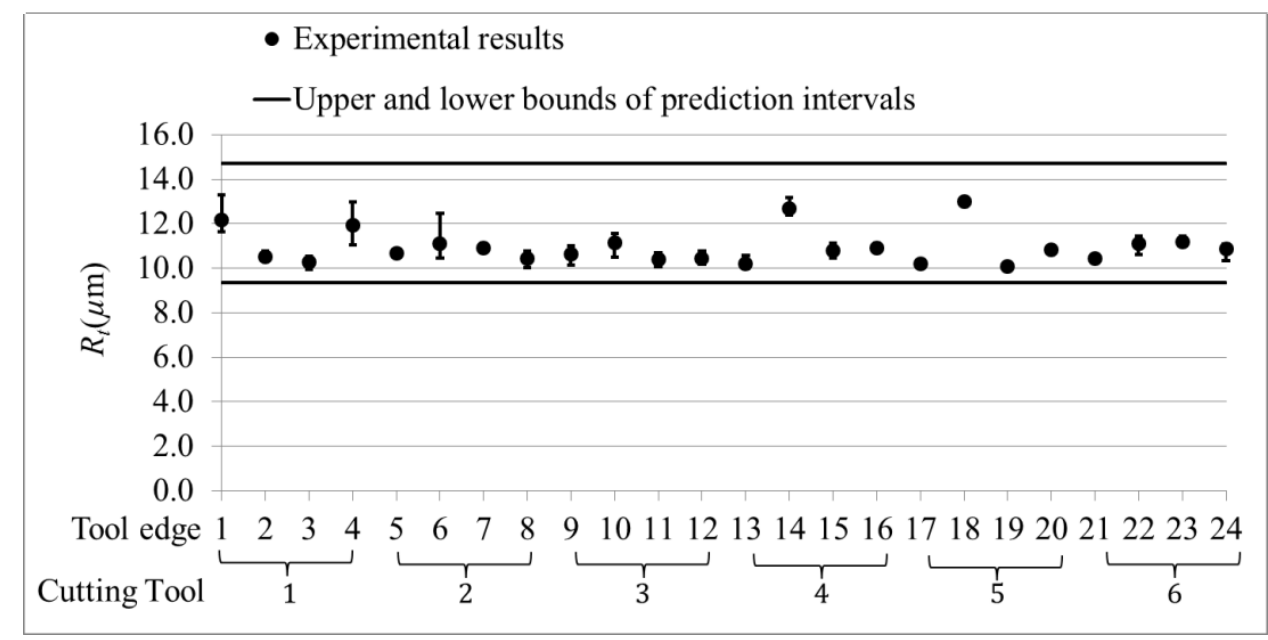

(b)

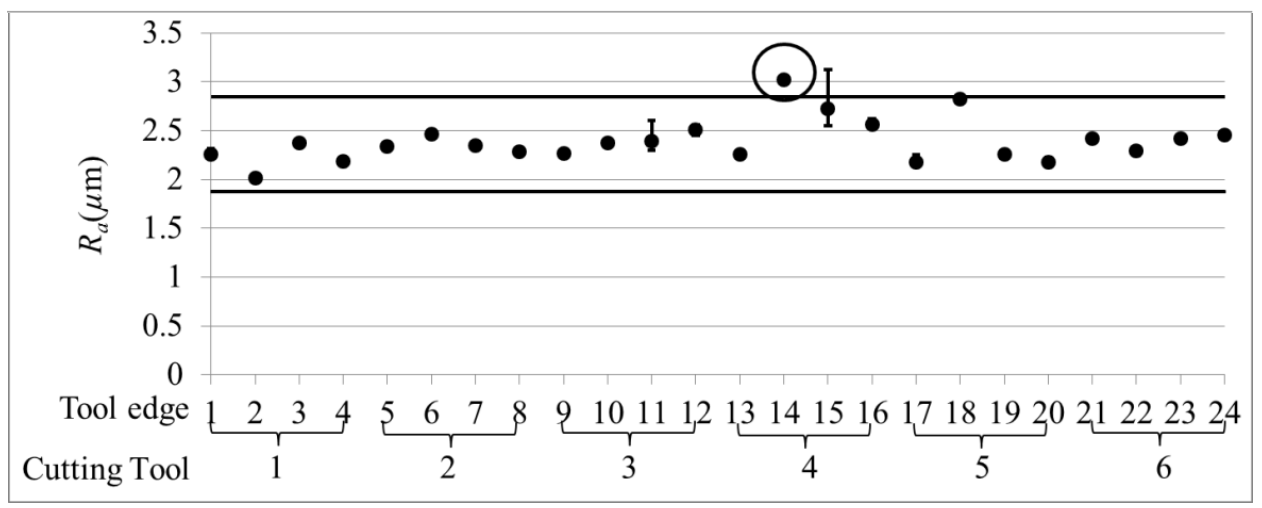

(c)

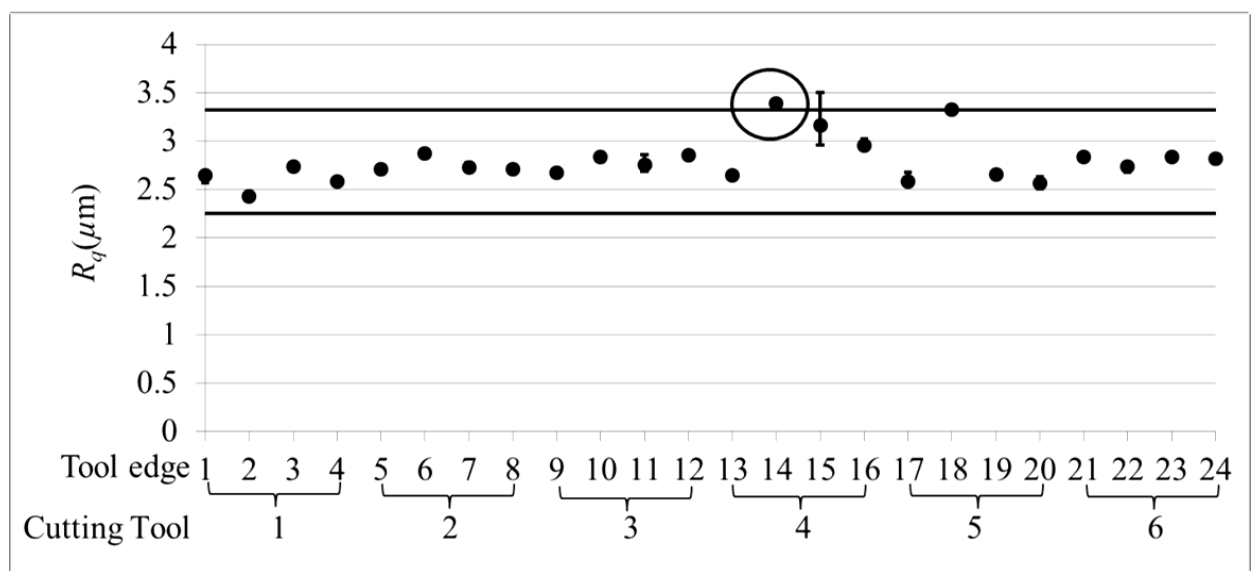

Figure 12: Experiment data and prediction intervals for: a) $R_{t}$, b) $R_{a}$ and c) $R_{q}$.

\section{ACKNOWLEDGEMENT}

The authors would like to thank Universiti Sains Malaysia for the offer of the RU(I) grant (no. 1001/PMEKANIK/814079) that resulted in this work. 


\section{REFERENCES}

[1] Cheung, C. F.; Lee, W. B. (2000). A theoretical and experimental investigation of surface roughness formation in ultra-precision diamond turning, International Journal of Machine Tools and Manufacture, Vol. 40, No. 7, 979-1002, doi:10.1016/S0890-6955(99)00103-0

[2] Patrikar, R. M. (2004). Modeling and simulation of surface roughness, Applied Surface Science, Vol. 228, No. 1-4, 213-220, doi:10.1016/j.apsusc.2004.01.010

[3] Asiltürk, I.; Çunkas, M. (2011). Modeling and prediction of surface roughness in turning operations using artificial neural network and multiple regression method, Expert Systems with Applications, Vol. 38, No. 5, 5826-5832, doi:10.1016/j.eswa.2010.11.041

[4] Madic, M.; Marinkovic, V.; Radovanovic, M. (2012). Mathematical modeling and optimization of surface roughness in turning of polyamide based on artificial neural network, Mechanika, Vol. 18, No. 5, 574-581, doi:10.5755/j01.mech.18.5.2701

[5] Bougharriou, A.; Bouzid, W.; Sai, K. (2014). Analytical modeling of surface profile in turning and burnishing, International Journal of Advanced Manufacturing Technology, Vol. 75, No. 1-4, 547-558, doi:10.1007/s00170-014-6168-x

[6] Sung, A. N.; Ratnam, M. M.; Loh, W. P. (2015). Effect of tool nose profile tolerance on surface roughness in finish turning, International Journal of Advanced Manufacturing Technology, Vol. 76, No. 9-12, 2083-2098, doi:10.1007/s00170-014-6430-2

[7] Chian, G. J.; Ratnam, M. M. (2011). Determination of tool nose radii of cutting inserts using machine vision, Sensor Review, Vol. 31, No. 2, 127-137, doi:10.1108/02602281111109989

[8] Skelton, R. C. (1969). Surface finish produced by a vibrating tool during turning, International Journal of Machine Tool Design and Research, Vol. 9, No. 4, 375-389, doi:10.1016/00207357(69)90021-3

[9] Lin, S. C.; Chang, M. F. (1998). A study on the effects of vibrations on the surface finish using a surface topography simulation model for turning, International Journal of Machine Tools and Manufacture, Vol. 38, No. 7, 763-782, doi:10.1016/S0890-6955(97)00073-4

[10] Qu, J.; Shih, A. J. (2003). Analytical surface roughness parameters of a theoretical profile consisting of elliptical arcs, Machining Science and Technology, Vol. 7, No. 2, 281-294, doi: $\underline{10.1081 / M S T-120022782}$

[11] Choudhury, I. A.; El-Baradie, M. A. (1997). Surface roughness prediction in the turning of highstrength steel by factorial design of experiments, Journal of Materials Processing Technology, Vol. 67, No. 1-3, 55-61, doi:10.1016/S0924-0136(96)02818-X

[12] Shahabi, H. H.; Ratnam, M. M. (2010). Prediction of surface roughness and dimensional deviation of workpiece in turning: A machine vision approach, International Journal of Advanced Manufacturing Technology, Vol. 48, No. 1-4, 213-226, doi:10.1007/s00170-009-2260-Z

[13] Wang, X.; Feng, C. X. (2002). Development of empirical models for surface roughness prediction in finish turning, International Journal of Advanced Manufacturing Technology, Vol. 20, No. 5, 348-356, doi:10.1007/s001700200162

[14] Lu, C. (2008). Study on prediction of surface quality in machining process, Journal of Materials Processing Technology, Vol. 205, No. 1-3, 439-450, doi:10.1016/j.jmatprotec.2007.11.270

[15] Lu, C.; Ma, N.; Chen, Z., Costes, J.-P. (2010). Pre-evaluation on surface profile in turning process based on cutting parameters, International Journal of Advanced Manufacturing Technology, Vol. 49, No. 5-8, 447-458, doi:10.1007/s00170-009-2417-9

[16] Kohli, A.; Dixit, U. S. (2005). A neural-network-based methodology for the prediction of surface roughness in a turning process, International Journal of Advanced Manufacturing Technology, Vol. 25, No. 1-2, 118-129, doi:10.1007/s00170-003-1810-Z

[17] Hessainia, Z.; Belbah, A.; Yallese, M. A.; Mabrouki, T.; Rigal, J-F. (2013). On the prediction of surface roughness in the hard turning based on cutting parameters and tool vibrations, Measurement, Vol. 46, No. 5, 1671-1681, doi:10.1016/j.measurement.2012.12.016

[18] Simunovic, G.; Simunovic, K.; Saric, T. (2013). Modelling and simulation of surface roughness in face milling, International Journal of Simulation Modelling, Vol. 12, No. 3, 141-153, doi:10.2507/IJSIMM12(3)1.219

[19] Lee, B. Y.; Yu, S. F.; Juan, H. (2004). The model of surface roughness inspection by vision system in turning, Mechatronics, Vol. 14, No. 1, 129-141, doi:10.1016/S0957-4158(02)00096-X 
[20] Cus, F.; Zuperl, U. (2015). Surface roughness control simulation of turning processes, Strojniski vestnik - Journal of Mechanical Engineering, Vol. 61, No. 4, 245-253, doi:10.5545/svjme.2014.2345

[21] Pare, V.; Agnihotri, G.; Krishna, C. (2015). Selection of optimum process parameters in high speed CNC end-milling of composite materials using meta heuristic techniques - a comparative study, Strojniski vestnik - Journal of Mechanical Engineering, Vol. 61, No. 3, 176-186, doi:10.5545/sv-jme.2014.1914

[22] Krolczyk, G.; Raos, P.; Legutko, S. (2014). Experimental analysis of surface roughness and surface texture of machined and fused deposition modelled parts, Technical Gazette, Vol. 21, No. $1,217-221$

[23] Wan, L.; Wang, D.; Gao, Y. (2015). Investigations on the effects of different tool edge geometries in the finite element simulation of machining, Strojniski vestnik - Journal of Mechanical Engineering, Vol. 61, No. 3, 157-166, doi:10.5545/sv-jme.2014.2051

[24] Karayel, D. (2009). Prediction and control of surface roughness in CNC lathe using artificial neural network, Journal of Materials Processing Technology, Vol. 209, No. 7, 3125-3137, doi:10.1016/j.jmatprotec.2008.07.023

[25] Kirby, E. D.; Chen, J. C. (2007). Development of a fuzzy-nets-based surface roughness prediction system in turning operations, Computers \& Industrial Engineering, Vol. 53, No. 1, 3042, doi:10.1016/j.cie.2006.06.018

[26] Khorasani, A. M.; Yazdi, M. R. S.; Safizadeh, M. S. (2012) Analysis of machining parameters effects on surface roughness: a review, International Journal of Computational Materials Science and Surface Engineering, Vol. 5, No. 1, 68-84, doi:10.1504/ijcmsse.2012.049055

[27] Siddhpura, M.; Paurobally, R. (2012). A review of chatter vibration research in turning, International Journal of Machine Tools and Manufacture, Vol. 61, 27-47, doi:10.1016/ j.ijmachtools.2012.05.007

[28] ISO 16610-21: 2011E (2011). Geometrical Product Specifications (GPS) - Filteration - Part 21: Linear profile filters: Gaussian filters, International Organization for Standardization, Geneva

[29] Ekstrom, C. T.; Sorensen, H. (2010). Introduction to Statistical Data Analysis for the Life Sciences, $1^{\text {st }}$ ed., CRC Press, Taylor \& Francis Group, Boca Raton

[30] Roush, M. L.; Webb, W. M. (2006). Applied Reliability Engineering, $5^{\text {th }}$ ed., The Center for Reliability Engineering, University of Maryland, College Park

[31] De Sá, J. P. M. (2007). Applied Statistics Using SPSS, STATISTICA, MATLAB and R, $2^{\text {nd }}$ ed., Springer-Verlag, Berlin 